\title{
The "secret" impact of population statistics on the metrics of diabetes
}

\begin{abstract}
The accuracy of disease metrics is dependent on the quality of population-based data. Many diseases, including diabetes, are age and sex dependant. Accurate age- and sexspecific population survey data, population estimates and projections are required to assess the scale and trends in the burden of these diseases.
\end{abstract}

No assessment of the quality of population data being used in the UAE diabetes metrics has been published. We provide insight into the availability and quality of published population data, which is currently being used to inform diabetes research and health services planning in the UAE.

We show the absence of credible population-based data impedes the accurate assessment of disease prevalence, incidence and trends. This means that many statements about the burden of this disease in relative and absolute terms are not robust.

There has been only one study of sufficient reliability of the prevalence of diabetes in the UAE and this was undertaken in 2000. Hence the calculation and reporting of trends is problematic. Population estimates for the UAE are based on out of date data and are extremely variable. Population projections for the UAE and other Middle East countries with large expatriate labour forces are improbable.

The clinical and other implications of accurate population-based metrics are wide reaching. If prevalence rates are to be used to guide public policy and infrastructure planning, then we need to use valid data, including population and population-based data.

Whilst specific reference is made to diabetes, and the issues affecting the United Arab Emirates and the Gulf Cooperation Council Countries of the Middle East; the impact of inaccurate population-based metrics have application in other regions, and other diseases.

Keywords: diabetes, population, population-based, metrics, estimates, projections, prevalence, incidence, mortality, united arab emirates
Volume I Issue 4 - 2014

\author{
Lyndal Heather Hunter,' Walter Frederick \\ Robb,' Sharon M Brownie ${ }^{2}$ \\ 'Adjunct Research Fellow, Griffith University, Australia \\ ${ }^{2}$ Professor International Nursing, Griffith University, Australia
}

Correspondence: Lyndal Heather Hunter, Adjunct Research Fellow, Griffith University, Population Health, 4222 Gold Coast Qld, Australia, Tel +97I503942256,

Email I.hunterrobb@griffith.edu.au, robbwflh@bigpond.net.au

Received: August 28, 2014 | Published: October 17, 2014
Abbreviations: DHA, dubai health authority; GCC, gulf cooperation council; HAAD, health authority abu dhabi; IDF, international diabetes federation; IGT, impaired glucose tolerance; MENA, middle east and north african region; $\mathrm{MOH}$, ministry of health; NBS, uae national bureau of statistics; SCAD, statistics centre abu dhabi; UAE, united arab emirates; WHO, world health organization

\section{Introduction}

In the United Arab Emirates (UAE), a grim picture is painted regarding the prevalence of diabetes and its impact on society. This picture is informed by global ${ }^{1-3}$ and regional research. ${ }^{4}$ Annual metrics show "alarmingly high" 1,5 diabetes and impaired glucose tolerance (IGT) prevalence in UAE, and other Gulf Cooperation Council (GCC) countries. The International Diabetes Federation (IDF) estimated 745,940 people in the UAE have diabetes in 2013 , with the comparative prevalence of diabetes in the adult population (20-79years) being $18.98 \%$. By comparison, the global comparative prevalence in 2013 is $8.26 \%{ }^{1}$

The alarming language contained in the IDF Diabetes Atlas ${ }^{1}$ is frequently restated in regional newspapers, where improvements in the world ranked position for diabetes prevalence are also presented as achievements. ${ }^{6}$ Consequently in the UAE and GCC, awareness that diabetes is a problem is high. IDF projections are that by 2035, in the Middle East and North African region (MENA), the number of people with diabetes (diagnosed and undiagnosed) will increase by $96.2 \%{ }^{1}$ The picture reported is of an aging population, with struggling health systems, ${ }^{7}$ both important drivers for public health expenditure in the UAE. ${ }^{8}$

The reliability of disease metrics is dependent on valid datasets being available. ${ }^{9}$ The reliability of IDF diabetes estimates for the UAE depends on the reliability of the underlying survey data ${ }^{4}$ and population estimates..$^{10,11}$ In generating the prevalence of diabetes and other metrics, the IDF uses the United Nation's (UN) adult population estimates (ages 20-79) as the data denominator, and undertakes age standardization of diabetes rates using the World Standard Population provided by the World Health Organization (WHO). ${ }^{12,13}$ Many diseases, including diabetes, are age and sex dependent. Accurate ageand sex-specific population survey data, population estimates and projections are required to assess the scale and trends in the burden of these diseases. ${ }^{1,12,14}$

No assessment of the quality of publicly available population data being used in the UAE diabetes metrics has been published. Examining the reliability of diabetes metrics for the UAE has offered 
more generic insights and lessons. This paper demonstrates the uncertainty that exists in population data and IDF calculations for the UAE. We show the absence of credible population-based data impedes the accurate assessment of disease prevalence, incidence and trends. This means that many statements about the burden of diabetes in relative and absolute terms are not robust.

\section{Diabetes metrics}

The key metrics of the scale of diabetes are listed in (Figure 1). All these rates are directly dependent on population-based estimates. The accuracy of total population estimates and the quality of population data could significantly affect the reliability of these metrics.

\begin{tabular}{|c|}
\hline $\begin{array}{l}\text { Age specific prevalence rates are estimated using survey data from well structured probability sampling, by } \\
\text { dividing the number of people with diabetes found in each age group in the sample by the total number sampled in } \\
\text { that age group. }\end{array}$ \\
\hline $\begin{array}{l}\text { Age/sex specific prevalence rates are estimated using survey data from well structured probability sampling, by } \\
\text { dividing the number of people with diabetes found in each age/sex group in the sample by the total number sampled } \\
\text { in that age/sex group }\end{array}$ \\
\hline $\begin{array}{l}\text { Estimated total number of persons with diabetes in a population is calculated by multiplying the age (or age/sex) } \\
\text { specific rates by the number of people of that age (or age/sex) group in the population. }\end{array}$ \\
\hline $\begin{array}{l}\text { The crude prevalence rate is the above estimate of the total numbers in the population divided by the total } \\
\text { population. This is called the "country prevalence rate" in IDF data. }\end{array}$ \\
\hline $\begin{array}{l}\text { An age standardized prevalence rate for a country is calculated by applying that country's age specific prevalence } \\
\text { rates to a standard population, usually a "world" population, to remove the effect of different age structure in } \\
\text { countries. This is the "comparative prevalence" rate used by IDF in global comparisons of diabetes prevalence. }\end{array}$ \\
\hline $\begin{array}{l}\text { Age/sex standardized prevalence rate for a country is calculated by applying that country's age/sex specific } \\
\text { prevalence rates to a standard population, usually a "world" population, to remove the effect of different age/sex } \\
\text { structure in countries }\end{array}$ \\
\hline $\begin{array}{l}\text { Incidence is the count of people in a population who have been diagnosed as having diabetes in a given time period } \\
\text { - the number of new cases. }\end{array}$ \\
\hline $\begin{array}{l}\text { The crude incidence rate is the incidence number divided by the total population. It is not used for comparison with } \\
\text { other populations. }\end{array}$ \\
\hline The crude death rate is the number of deaths divided by the population, usually presented per 1,000 populations \\
\hline The age/sex specific mortality rate is the deaths per 1,000 populations of age/sex groups \\
\hline Diabetes related mortality rates are deaths per 1,000 where cause of death is diabetes. Usually relates to $\mathrm{p}$ \\
\hline
\end{tabular}

Figure I Key metrics of diabetes.

\section{Quality of population data and estimates for UAE}

\section{Population estimates}

There is significant uncertainty in total population estimates for the UAE. UN world population estimates and projections ${ }^{15}$ rely heavily upon official country data, last available for UAE in $2010 .^{10}$ The UN produces estimates structured in 5year age intervals, which can be compared against the WHO's World Standard Populatio ${ }^{13}$ for international comparison of populations. The UAE has not published population estimates by 5year age groups since the last national census undertaken in 2005.

Official UAE population estimates are based on the latest national census undertaken in 2005; birth and death data available from the Ministry of Health (MOH), Health Authority Abu Dhabi (HAAD) and Dubai Health Authority (DHA); and net migration data available from Ministry of Interior.

Other population estimates may show considerable variance from those produced by the UAE National Bureau of Statistics (NBS) and by UN. The range of population estimates are listed in (Figure 2), ${ }^{16-27}$ and graphed in (Figure 3). The WHO, World Bank and IDF all use UN population estimates and projections in their metrics. As shown in Figure 3, for 2010, the highest value is $79 \%$ greater than the lowest value.

Unofficial or other population statistics influence health policy and practice in UAE. To generate health metrics for Abu Dhabi, HAAD uses its own population estimates ${ }^{28}$ which are higher than those produced by the NBS or the Statistics Centre Abu Dhabi (SCAD).
Researchers with HAAD's Weqaya programme, which achieved almost complete cardiovascular risk factor screening of the citizen population in the emirate of Abu Dhabi indicate "there may have been inaccuracies in the population figures used as denominators here, which were derived from a 2005 census". ${ }^{29}$ Blair \& Sharif ${ }^{30}$ call the 2009 population estimation "improbable" and point out that high population growth means that population counts enumerated in formal censuses quickly become inaccurate. UAE newspapers ${ }^{31,32}$ also report a lack of confidence in NBS population estimates for planning purposes. The National newspaper reports in 2011 "the lack of a census in 2010 means more exact figures are unavailable". ${ }^{33}$

\section{Population growth}

As a population grows, both the absolute number of people with diabetes and the "burden of disease" increase, even if the prevalence remains the same. Exponential growth, significantly greater than other GCC countries and world growth, has been the most dramatic feature of the UAE population. ${ }^{34}$ Projected population growth is expected to be similar to other GCC countries and greater than world rates as shown in Figure 4.

\section{Population constituency and gender}

Like all GCC countries, demographic reporting in the UAE is usually limited to "citizens" and "non-citizens". The nationalities of the $88.5 \%$ of the UAE population who are expatriates are not publically available. Yet these sub-populations have very different demographic characteristics, particularly age structure, gender balance and growth, and different diabetes prevalence. ${ }^{4}$ These unusual population features impact upon the prevalence, incidence and mortality of diabetes in the UAE. 


\begin{tabular}{|c|c|c|c|}
\hline Total population estimate & Source & Reference year & Date published \\
\hline $5,473,972$ & CIA Factbook ${ }^{16}$ & 2013 & Jul-I3 \\
\hline $5,524,000$ & International Monetary Fund ${ }^{17}$ & 2013 & - \\
\hline \multirow{2}{*}{$9,346,000$} & United Nations $^{18}$ & 2013 & 2013 \\
\hline & World Bank ${ }^{19}$ & 2013 & - \\
\hline \multirow{2}{*}{$9,206,000$} & World Health Organization ${ }^{20}$ & 2012 & 2014 \\
\hline & World Bank ${ }^{19}$ & 2012 & - \\
\hline $8,100,000$ & Population Reference Bureau ${ }^{21}$ & 2012 & 2012 \\
\hline \multirow{2}{*}{$8,925,000$} & World Bank ${ }^{19}$ & 2011 & - \\
\hline & World Health Organization ${ }^{22}$ & 2011 & 2014 \\
\hline \multirow{2}{*}{$7,891,000$} & World Health Organization ${ }^{23}$ & 2011 & 2013 \\
\hline & Britannica $^{24}$ & 2011 & 2012 \\
\hline \multirow[t]{2}{*}{$8,925,000$} & World Bank ${ }^{19}$ & 2011 & - \\
\hline & United Nations ${ }^{18}$ & 2010 & 2012 \\
\hline \multirow[t]{2}{*}{$8,442,000$} & World Health Organization ${ }^{22}$ & 2010 & - \\
\hline & World Bank ${ }^{19}$ & 2010 & - \\
\hline \multirow{2}{*}{$8,264,000$} & National Bureau Statistics, UAE ${ }^{10}$ & 2010 & Mar-II \\
\hline & WHO, EMRO 25 & 2010 & - \\
\hline \multirow{3}{*}{$7,5 \mid 2,000$} & United Nations" & 2010 & 2011 \\
\hline & World Health Organization ${ }^{23}$ & 2010 & 2012 \\
\hline & World Bank ${ }^{19}$ & 2010 & - \\
\hline $5,400,000$ & Population Reference Bureau ${ }^{23}$ & 2010 & 2010 \\
\hline $5,055,000$ & International Monetary Fund ${ }^{24}$ & 2010 & 2010 \\
\hline $4,707,000$ & World Bank ${ }^{26}$ & 2010 & I-Jul-II \\
\hline $7,718,319$ & World Bank ${ }^{19}$ & 2009 & 2014 \\
\hline $4,106,427$ & National Bureau Statistics, UAE (Census) ${ }^{27}$ & 2005 & 2005 \\
\hline
\end{tabular}

Figure 2 Common estimates of Total Population: UAE.

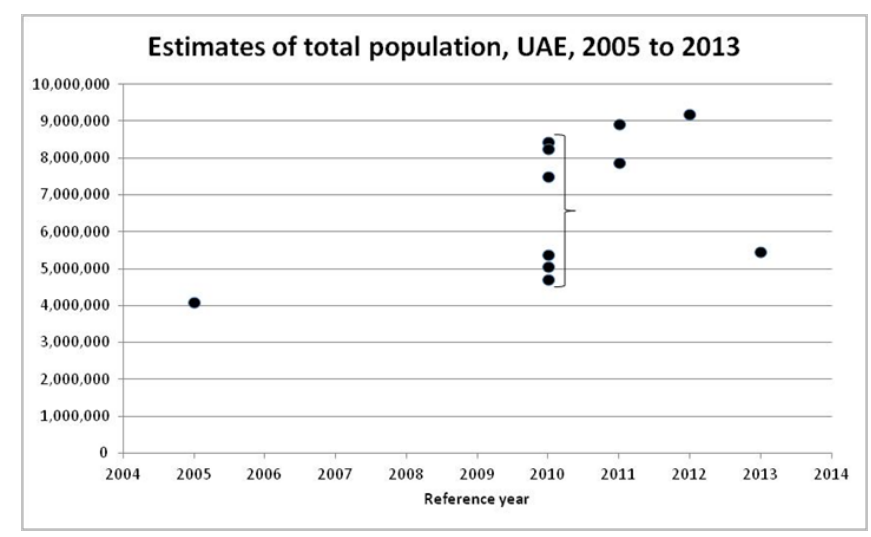

Figure 3 Range of population estimates for UAE, 2005-20I3.

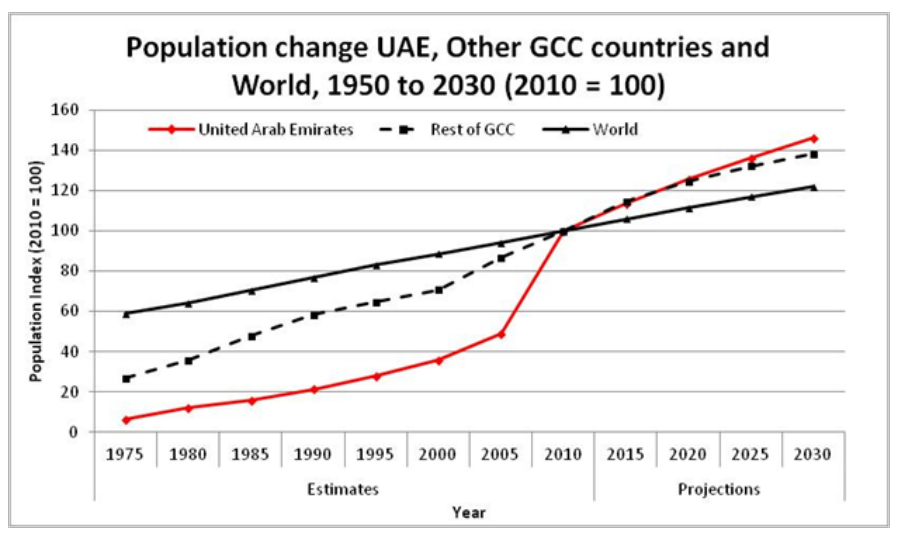

Figure 4 Population change, other GCC and World, I 950 to 2030. 
UAE has a known population and gender imbalance, generated by large numbers of young, single, mainly male expatriate workers. ${ }^{34}$ Between 1995 and 2005, the non-citizen population structure in the UAE saw large increases in percentages in males aged 20 to 34 ; small decreases in males 35 to 49 ; small increases in males aged 50 to 64years; small increases in females in most age groups from 20 to 64years; and large decreases in percentages in age groups less than 20years. (Figure 5) The non-citizen profile clearly demonstrates UAE's increased dependence on temporary migrant workers. By 2010 , citizens comprised just $11.5 \%$ of the total population of UAE. ${ }^{10}$

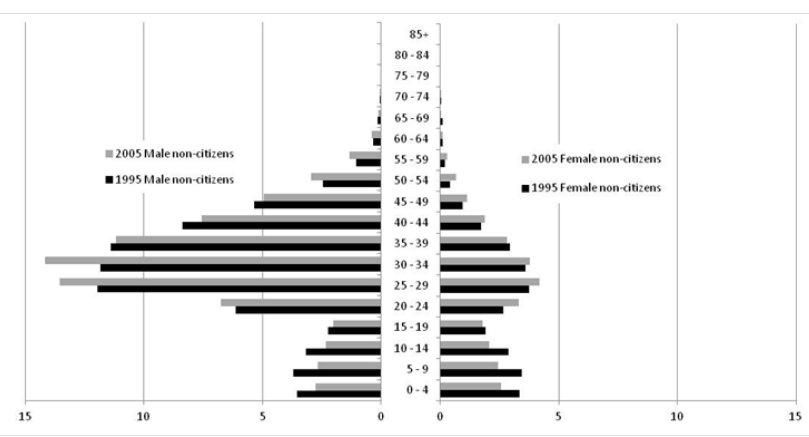

Figure 5 Population structure changes for non-citizens UAE 1995 to 2005.

\section{Population ageing}

Like other countries in the GCC, UAE is a young population. According to UN World Population Prospects $2012,{ }^{35}$ by 2050, the UAE population will age substantially. By 2050 , the UN estimates that the percentage of the population under 15years will drop (from $20.0 \%$ to $11.2 \%$ ). The $60-79$ years group will grow (from $0.6 \%$ to $32.8 \%)$. The bulk of the population $(54.7 \%)$ will be aged $15-59$ and just $1.2 \%$ will be over 80 years. If correct, the prevalence of diabetes, and the burden on the UAE health system would increase significantly (Figure 6).

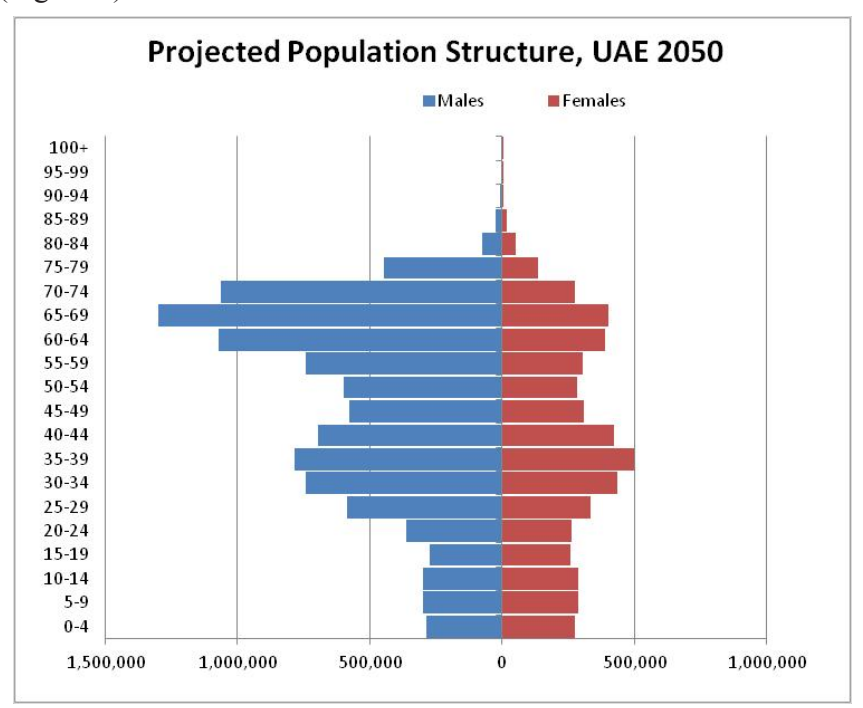

Figure 6 Projected population structure, UAE 2050.

However, as we will show, the UN wrongly ages the transient noncitizen population, skewing the population profile towards increased numbers of elderly men and women. In fact, only the profile of the small citizen sub-population is aging.

An official NBS population profile for UAE is not available.
Instead, Abu Dhabi Emirate's 2012 population estimates (Figure 7) will demonstrate the difference between citizen and non-citizen population structure, and illustrate the reason why the 2012 UN World Population Prospects are improbable.

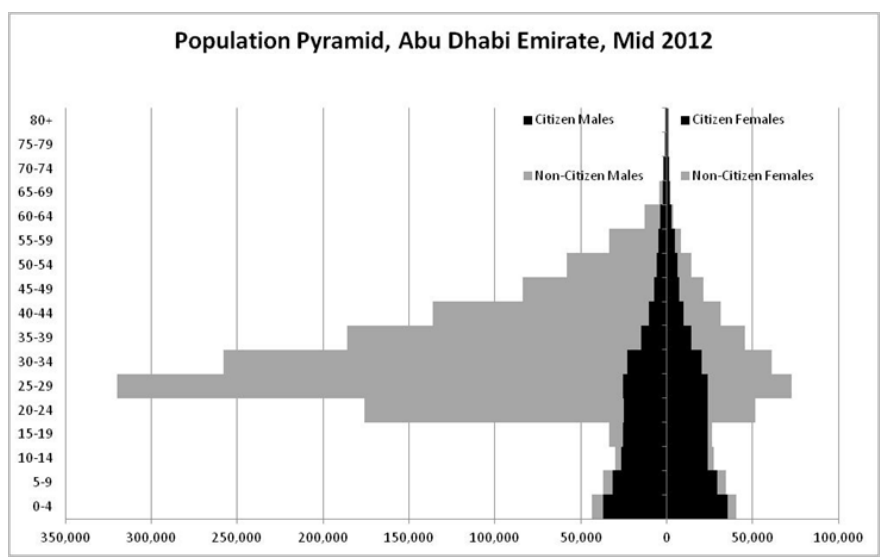

Figure 7 Population structure,Abu Dhabi Emirate, mid-2012

The Abu Dhabi citizen sub-population shown at the core of the population profile demonstrates a traditional population pyramid of a young population having more than replacement size families. As this population ages, the crude prevalence of diabetes will increase for citizens.

The non-citizen sub-population consists of a large, young largely male, adult migrant population come to work, but not to settle, they stay several years, and return home before 65 years of age. ${ }^{9}$ This is clear in the population profile.

Whilst the citizen population profile of the Abu Dhabi ages; the non-citizen population profile does not. The non-citizen population is constantly replaced by new workers of the same age range. While the factors creating the population imbalance remain the same, the status quo population and gender imbalance will be preserved.

In Figure 8 it can be seen that between 2005 and 2012, the main growth in non-citizen population for Abu Dhabi Emirate is for males at ages between 20 and 34years, and that the percentage of the population in almost all age groups over 35years has decreased for both males and females. Population shares below the age of 20years have reduced. In Abu Dhabi, as in UAE as a whole, the non-citizen replacement sub-population cohort does not age. There are very few non-citizens aged over 65 and over. Therefore, increases in diabetes incidence due to ageing are limited to that from citizens.

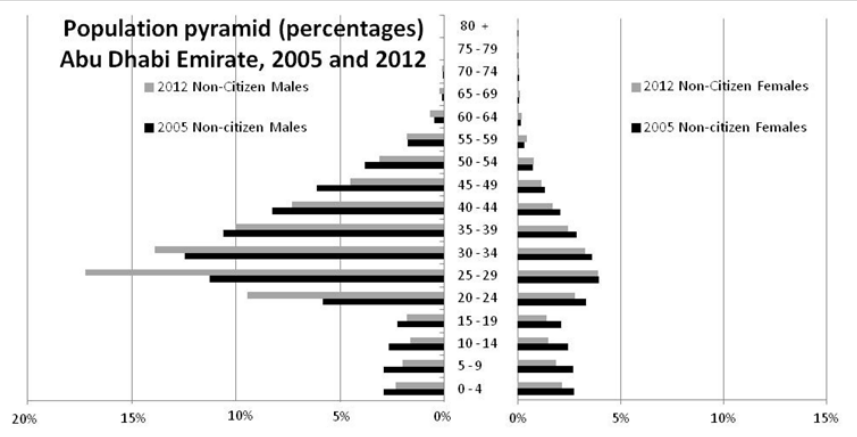

Figure 8 Non-citizen Population structure, Abu Dhabi Emirate, 2005 and 2012. 


\section{Quality of diabetes metrics}

\section{Diabetes prevalence}

In the UAE, just one study has continuously informed the IDF estimation of diabetes prevalence. ${ }^{36}$ This population-based survey undertaken by Malik et al. ${ }^{4}$ in 1999-2000, excluded all expatriate workers living in labour camps. These workers are included in UAE census counts and population estimates. They represent a very large segment of the young adult population aged 20 to 39 .

Their exclusion from Malik's study has the potential to bias prevalence estimates to the extent that rates for these people differ from others in the population. For example, the Malik study identified that age-adjusted diabetes prevalence ranged from $15.9 \%$ for people from Jordan, Palestine, Syria, Lebanon and Iraq; to $20.9 \%$ for people from South Asia, compared with $25.1 \%$ for UAE citizens. Clearly, the exclusion of a large number of expatriates would result in higher National prevalence rates.

There is no real basis for an assertion that diabetes prevalence is increasing in the UAE population. To assess trends in diabetes prevalence, regular well-structured population surveys using appropriate diagnostic tools are required, particularly to assess whether prevalence is increasing for each age/sex group. This has not occurred in UAE, so there is no valid way to judge whether age/sexspecific rates underlying national prevalence rates are changing over time.

The Weqaya programme, which achieved around 95\% health surveillance penetration of the Abu Dhabi citizen population from 2008-2012, may provide useful confirmation of diabetes prevalence rates among the citizen population. However the data and data collection methodology is not publicly available. Weqaya data is not referenced by IDF.

Undiagnosed diabetes is starting to trend down in the USA ${ }^{37}$ and Kuwait ${ }^{38}$ possibly demonstrating the effectiveness of health promotion and public awareness programs, ${ }^{39}$ such as are made in the UAE. Forward projections including high estimates for undiagnosed diabetes may be suspect in UAE and other counties where the public and clinical profile of diabetes is high. ${ }^{40}$

\section{Diabetes incidence}

There is no publicly available data on diabetes incidence at the UAE level. We do not know how many new cases are diagnosed each year, or the number of people living with a diagnosis of diabetes. We are unable to calculate age/sex- or age/sex/citizenship-specific rates.

\section{Diabetes-related mortality rates}

Despite the comparatively high prevalence of diabetes in the UAE, ${ }^{1}$ diabetes still does not show up prominently in UAE death records. In 2010 , around $4.14 \%$ of all deaths (both citizens \& non-citizens) were attributed to diabetes. However, for $10.8 \%$ of all deaths the cause was "not stated". This may indicate that diabetes related mortality is understated. ${ }^{40,41}$ About $80 \%$ of the recorded diabetes deaths were in the age range 20 to 79 years, ${ }^{41}$ the age range of interest to the IDF.

In the absence of available official UAE population estimates by age group, gender and citizenship, diabetes-related mortality rates can only be calculated using the UN population estimates for 2010. These indicate the rates rise from 0.2 per 1,000 for age group 55-59years to 2.3 per 1,000 for $65-69$ then increasing to 7.11 per 1000 for age group 70-74years up to 11.1 for those $80+$ (Figure 9). This means that population estimates for the older age groups are the most critical in the calculation of diabetes metrics.

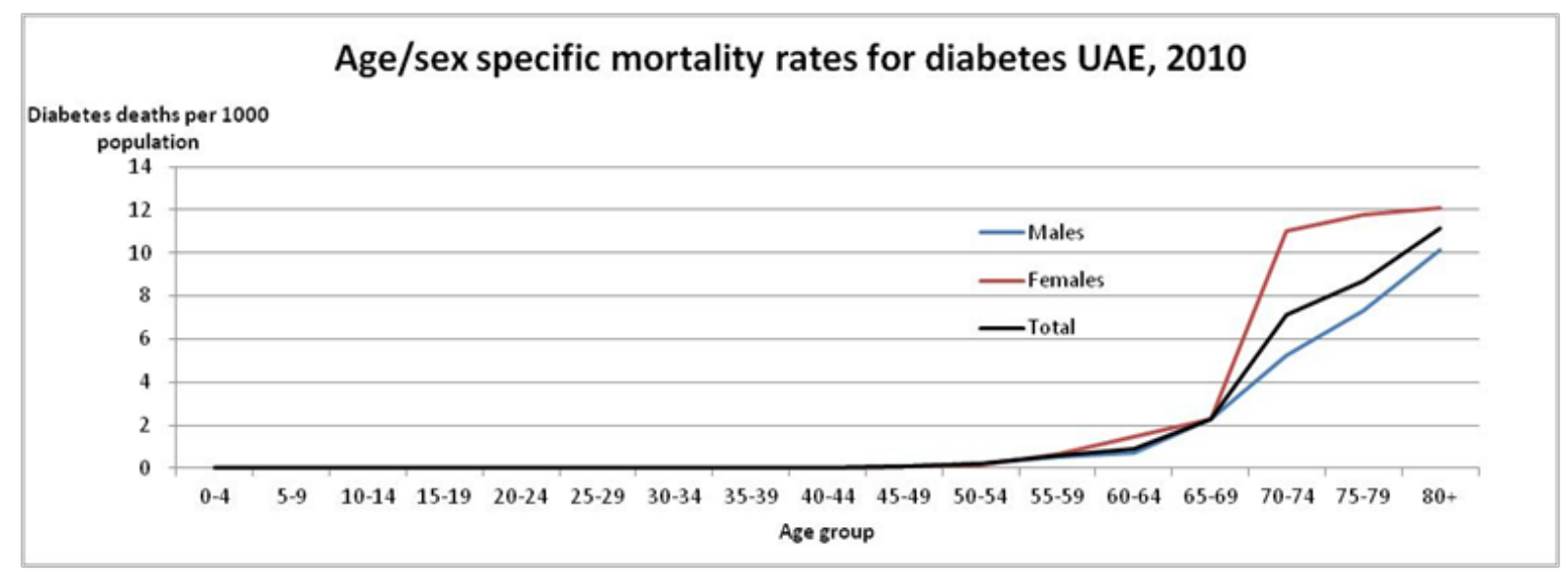

Figure 9 Age/sex-specific mortality rates for diabetes UAE, 2010.

\section{Impact}

The implications of inaccurate population-based metrics are wide reaching.

\section{Impact of population data on diabetes metrics}

Changes in diabetes metrics can occur on the basis of differences in the following population-based statistics:

i. The total population.

ii. The population structure by age and sex, and by nationality/ ethnicity. iii. Age/sex-specific prevalence rates.

If the total population estimate for people aged 20-79years is higher than actual, then:

i. Estimates of the number of people with diabetes will be overstated.

ii. Incidence rates will be understated.

iii. Diabetes-related mortality rates will be understated.

If the population estimates over state the percentage of the population in older age groups: 
i. Estimates of the number of people with diabetes will be overstated.

ii. Crude prevalence rates will be overstated.

iii. Age-specific mortality rates will be understated.

If the population estimates understate the percentage of the UAE population who are expatriates:

i. Estimates of the number of people with diabetes will be overstated.

ii. Crude prevalence rates will be overstated.

Given the impact of population data on diabetes metrics, it is important that collection of statistics includes all relevant population characteristics and can be related to the relevant subpopulations. A true picture of the UAE population would recognize the presence and demographic characteristics of its sub-populations.

\section{Impact on health service planning and delivery}

The UAE invests heavily in health infrastructure and best practice health service delivery. If diabetes prevalence rates are to be used to guide public policy, resource and infrastructure planning, then valid data is critical, including population and population-based data. The prevention and management of diabetes and related noncommunicable diseases (NCD) within the UAE is based on population data, which may be the best available, but is not recognized to be of sufficient reliability within the UAE.

UAE has become a hub for medical infrastructure and career investment, and for medical tourism. Outdated IDF rankings are sometimes cited $^{7,42}$ alongside newer IDF data to make a point. The IDF Atlas ${ }^{1}$ provides an annual view of diabetes globally, regionally and at country level. They caution against longitudinal use of their data and metrics. IDF data cannot be used to demonstrate an increase or decrease in comparative prevalence because of profound changes in methodology in 2011, which are implemented in the 5th Edition of the Atlas. ${ }^{12,43}$ Crude prevalence of diabetes in the UAE (the prevalence within UAE, using UAE population count) cannot be used for comparative purposes within the UAE as these rates are based on just one study; or externally because of differences in the population structure and dynamics of other countries. In the absence of publically available unambiguous data, people will draw wrong conclusions and health planning will be flawed.

\section{Impact on clinical research}

Clinical studies also should be representative of the population. Insufficient sample size and sampling bias can undermine the usefulness of results. Inappropriate selection of study participants and controls can mislead results. For instance, in 2006, $\mathrm{WHO}^{44}$ addressed inconsistent diagnostic criteria which had limited the usefulness of much diabetes research. Chiefari $\mathrm{E}$ et al. ${ }^{45}$ who investigated the association of Diabetes mellitus Type 2 with genetic variants discussed the significant difficulty in defining the appropriate control group to exclude individuals with insulin resistance. As diabetes is an age-related disease, given that its prevalence increases with the age, choosing young subjects as controls could involve the erroneous enrollment of individuals not yet diabetic.

\section{Clinical implications}

Clinicians would be aware of the population characteristics (e.g. aging) most associated with diabetes, but may not be aware of the actual extent of the disease and the real trends. While clinical impression may confirm high prevalence for diabetes, there is insufficient available evidence to suggest that the prevalence of diabetes in either the citizen or non-citizen population is increasing. Clinical impression may also suggest that diabetes is diagnosed at younger age groups than elsewhere, but without population and diabetes data available in standard 5year age groupings, there is also insufficient evidence to support this comparison.

Without accurate, timely information UAE clinicians may be led to practices that do not reflect the actual likelihood of patients having diabetes. The fact that Malik et al. ${ }^{4}$ estimates that over $40 \%$ of all people aged $55+$ years in UAE had diabetes, that over $40 \%$ of all people with diabetes were undiagnosed, and that citizens are much more likely to have diabetes should impact on diagnostic alertness and practice in UAE. The extent to which these statistics are out of date should also be of concern to clinicians.

All clinicians are urged to take note that the quality of health statistics depends not only on how well and often governments undertake population census, carry out health surveillance and manage health data collections; but how well doctors fill out the 'dreaded paperwork'! For instance, doctors can attend to underreporting and sparse cause-of-death data. WHO guidelines are available for death certification. ${ }^{46}$ Practical guidelines ${ }^{47}$ recommend that diabetes can be recorded as the "immediate cause of death" or the "underlying cause of death" but that more often than not these causes are not in the sequence of events leading to death. Diabetes is more often a "contributory cause of death", and should be recorded in this manner. In perinatal deaths, diabetes may be recorded as a "maternal disease affecting the infant". 48

\section{Conclusion}

Valid data sets are essential to health service planning, effective disease prevention strategies and early diagnosis and treatment. This study has identified a number of issues with population data and diabetes metrics in the UAE.

i. Publicly available estimates of total population of the UAE have varied by as much as $79 \%$.

ii. The latest available official population estimates relate to 2010 and these are based on 2005 census data.

iii. There is no publicly available data on the structure of the population in the UAE since 2005.

iv. Given that the UAE population is substantially composed of male non-citizens who are replaced, the ageing of the population is limited to the citizens' portion of the population.

v. There are no projections of the population of the UAE that adequately address the expatriate population.

vi. Only one prevalence study of sufficient quality has been done for UAE. This was in 1999-2000, is now out of date, and excluded the large population of people resident in workers camps.

While these issues are by no means unique to the UAE, to plan future services for diabetes, the above gaps in population data need to be addressed, particularly time series of prevalence rates.

\section{Acknowledgements}

None 


\section{Conflict of interest}

The authors declare that there is no conflict of interest.

\section{References}

1. International Diabetes Federation. IDF Diabetes Atlas. 6th ed. Brussels, Belgium; 2013.

2. Lozano R, Naghavi M, Foreman K, et al. Global and regional mortality from 235 causes of death for 20 age groups in 1990 and 2010: a systematic analysis for the Global Burden of Disease Study 2010. The Lancet. 2012;380(9859):2095-2128.

3. Lim SS, Vos T, Flaxman AD, et al. A comparative risk assessment of burden of disease and injury attributable to 67 risk factors and risk factor clusters in 21 regions, 1990-2010: a systematic analysis for the Global Burden of Disease Study 2010. The Lancet. 2012;380(9859):2224-2260.

4. Malik M, Bakir A, Abi Saab B, et al. Glucose intolerance and associated factors in the multi-ethnic population of the United Arab Emirates: results of a national survey. Diabetes Res Clin Pract. 2005;69(2):188-195.

5. Hirst M. The World Diabetes Congress in Dubai: a personal view. Diabetes Voice. 2012;57(1):34

6. Staff Reporter. UAE steps down in diabetes ranking. Khaleej Times. 2012 .

7. Booz Allen Hamilton. Exploring the growing challenge of diabetes across the GCC and within the United Arab Emirates. Booz Allen Hamilton Inc. 2012;3-19.

8. Koornneef EJ, Robben PB, Al Seiari MB, et al. Health system reform in the Emirate of Abu Dhabi, United Arab Emirates. Health Policy. 2012;108(2-3):115-121.

9. Brownie S, Hunter L, Robb W, et al. Diabetes in the United Arab Emirates: the need for valid datasets for health service planning. The Lancet Diabetes Endocrinol. 2014;2(7):535-537.

10. UAE National Bureau of Statistics. Methodology of estimating the population in UAE (2006-2010). 2010.

11. United Nations Population Division. World Population Prospects The 2010 Revision: Volume I: Comprehensive Tables: ST/ESA/SER.A/313. New York, USA; 2011

12. Guariguata L, Whiting D, Weil C, et al. The International Diabetes Federation Diabetes Atlas methodology for estimating global and national prevalence of diabetes in adults. Diabetes Res Clin Pract 2011;94(3):322-332

13. Ahmad OB, Pinto CB, Lopez AD, et al. Age standardization of rates: A new WHO Standard. Geneva: World Health Organisation; 2001.

14. Bonita R, Beaglehole R, Kjellstrom T. Basic epidemiology. Geneva Switzerland: WHO Publication; 2006.

15. United Nations Population Division. World Population Prospects, The 2012 Revision, Volume 1: Comprehensive Tables: ST/ESA/SER.A/336 New York, USA; 2013.

16. Central Intelligence Agency: The World Factbook.

17. International Monetary Fund. World Economic Outlook Database: Report for Selected Countries and Subjects: UAE Population (2010 -2013). 2014.

18. United Nations, DESA. World Population Prospects The 2012 Revision. Vol1: Comprehensive Tables. 2013.

19. World Bank. Databank: Population, total. 2014.

20. World Health Organization. Non-communicable Diseases Country Profiles, UAE 2014. 2014.
21. Population Reference Bureau. 2012 World Population Data Sheet. Washington, DC, USA; 2012.

22. World Health Organization: Global Health Observatory, UAE, Statistics Summary 2002-present.

23. World Health Organization. Noncommunicable diseases country profiles, 2010 and 2011. United Arab Emirates, Geneva; 2011.

24. Britannica Book of the Year. United Arab Emirates; 2012. 478p.

25. World Health Organisation, EMRO. The work of WHO in the Eastern Mediterranean Region. Cairo: Annual report of the Regional Director. 2011.

26. Population Reference Bureau. 2010 World Population Data Sheet Washington, DC, USA; 2010.

27. World Bank. World Development Indicators Database. 2011

28. UAE National Bureau of Statistics. National Census. 2005.

29. Health Authority Abu Dhabi. Health Statistics 2012, Reliable excellence in healthcare. 2013.

30. Hajat C, Harrison O, Al Siksek Z. Weqaya: A population-wide cardiovascular screening program in Abu Dhabi, United Arab Emirates. Am J Public Health. 2012;102(5):909-914.

31. Blair I, Sharif AA. Population structure and the burden of disease in the United Arab Emirates. J Epidemiol Glob Health. 2012;2(2):61-71.

32. Fitch A. Plea for population figures from the people who count. The National, Abu Dhabi. 2006.

33. Habboush M. Population rise sparks census calls. The National, UAE. 2010 .

34. Shaheen K. UAE to draft population strategy to address 'imbalance'. The National, Abu Dhabi. 2011.

35. The Economist Intelligence Unit. The GCC in 2020: The Gulf and its people. A report of the Economic Intelligence Unit. The Economist. 2009:1-20.

36. United Nations Population Division. World Population Prospects, The 2012 Revision: Volume II: Demographic Profiles: (ST/ESA/SER.A/345) New York, USA; 2012.

37. International Diabetes Federation. IDF Diabetes Atlas. 6th ed. References used for estimates of diabetes in adults. 2013

38. Selvin E, Parrinello C, Sacks D, et al. Trends in prevalence and control of diabetes in the United States, 1988-1994 and 1999-2010. Ann Intern Med. 2014;160(8):517-525.

39. Ahmed F, Waslien C, Al-Sumaie MA, et al. Trends and risk factors of hyperglycemia and diabetes among Kuwaiti adults: National Nutrition Surveillance Data from 2002 to 2009. BMC Public Health. 2013;13:103.

40. Pennington R. Thousands walk $5 \mathrm{~km}$ at Yas Marina Circuit to promote healthy living. The National. 2013.

41. UAE National Bureau of Statistics. Births and Deaths 2010, Table 3: Registered deaths (Citizens and non-citizens) by Sex and Cause of Death, 2010 UAE National Bureau of Statistics. 2012.

42. UAE Ministry of Health. Statistics 2010: Table 14: Distribution of Death by Cause, Sex, Nationality and Age Group. Abu Dhabi, UAE. 2010.

43. Booz Allen Hamilton. Fostering Dialogue to Address the diabetes crisis in the UAE: Business leaders collaborate on workplace strategies: A call to collective action. 2012.

44. International Diabetes Federation. IDF Diabetes Atlas, 5th ed. Brussels, Belgium; 2011. 
45. World Health Organization, International Disease Federation. Definition and Diagnosis of Diabetes Mellitus and Integrated Hyperglycaemia: Report of a WHO/IDF Consultation. Geneva, Switzerland; 2006.

46. Chiefari E, Tanyolac S, Paonessa F, et al. Functional Variants of the HMGA1 Gene and Type 2 Diabetes Mellitus. JAMA. 2011;305(9):903-912.
47. World Health Organization. International statistical classification of diseases and related health problems 10th Revision 2010. 2011.

48. Health Information Systems Knowledge Hub (circa 2012) Practical Guide: Handbook for Doctors on cause-of-death certification: Health Information Systems Knowledge Hub, School of Population Health University of Queensland. 